\title{
Staff Perception towards Leadership in Transforming Wolaita Sodo University: Qualitative Inquiry
}

\author{
Mulatu Dea Lerra \\ Department of Educational Planning and Management, Addis Ababa University, Addis Ababa, Ethiopia \\ Email: lerramulee2010@gmail.com, mulatudea83@yahoo.com
}

Received 7 July 2014; revised 10 August 2014; accepted 19 September 2014

Copyright (C) 2014 by author and OALib.

This work is licensed under the Creative Commons Attribution International License (CC BY). http://creativecommons.org/licenses/by/4.0/

(c) (i) Open Access

\begin{abstract}
In the stir of the competitive era of education today, higher education institutions (HEIs) attempt to advance themselves in academic programs, researches and innovations. To this end, they need to transform to realize such aspiration. This study was designed to look at staff perception toward leadership in transforming Wolaita Sodo University. Qualitative research design and case study method are used under the study. Part of the data was collected from a sample of 15 participants. The sample colleges and administration divisions, college deans, department heads, academic and supportive staff were selected through purposive sampling. The tools used to gather relevant data were interview, FGD, and relevant document analysis. Findings of the study revealed that attempt to transform the skill and competence of academic and supportive staff and students' learning are found to be insignificant; the top academic leaders focus on routine and administrative issues at the expense of emphasis on strategic matters, and changing the prevailed institutional culture. Moreover, there is lack of empowerment of the middle and first line managers who are highly engaged in operationalzing transformation process. Hence, change at Wolaita Sodo University lacks transformational dimension and the change may not make its intended goals. The study recommended that the transformation should primarily focus on developing people through empowering them and giving them responsibilities. The transformational leaders should focus on strategic issues instead of wasting time in changing and re-changing structures. The government needs to avail adequate budget and personnel to help the transformation. The University should also diversify its sources of income instead of relying on government subsidy, and should be autonomous to run its own affairs without direction or influence from any level of government.
\end{abstract}

\section{Keywords}

Change, Leadership, Reform, Transformational Leadership, Transformation

Subject Areas: Education, Information Science 


\section{Introduction}

Higher education institutions are of supreme importance for economic and social development, support teaching and training programs, which are designed to reply directly to the identified needs of specific contexts. They also promote innovation, encourage research to strengthening the social function, inculcating relevant knowledge and advanced skills, and provide the human resources required for leadership, management, business and professional positions [1]. Moreover, the institutions serve as the major research establishments that generate, adopt and pass knowledge. Higher education is, therefore, critical for economic progress, political stability and peace, as well as building democratic culture and cohesive societies.

In the stir of competitive era of education today, higher education institutions (HEIs) attempt to advance themselves in academic programs, research and innovation, and towards academic excellence. To this end, they need to transform to realize such aspiration. Globally, higher education systems have been influenced by the concept transformation. Like that of other countries, higher education in Ethiopia is going through a decisive phase of reform and expansion. As a system, it is increasingly required to respond and gear adequately to the development needs of the society and the country [1] [2].

Higher education in Ethiopia confronted with formidable challenges in many of them will require substantial changes in the existing institutional culture of "command and control" that characterizes the MoE and the government in general [2]. Other scholars argued that, the gap between the societal expectations and the actual performance of HEIs in Ethiopia became a serious concern among many people [3]. Thus, reforms are made at all levels. One of the Universities carrying out the intended change is Wolaita Sodo University. The University is led by transformational change framework that emphasizes on economic development and University enterprise cooperation. The change process has been six years' attempt, which started in March 2008 throughout the country and in 2010 at Wolaita Sodo University. Hence, the purpose of this paper is to investigate staff perception towards University leadership in transforming Wolaita Sodo University.

\section{Statement of the Problem}

Multiple layers of management, centralized and expensive systems as well as the accumulation of control procedures and regulations remain to be formidable obstacles in ensuring efficiency, economy and productivity of public sector organizations [2]. Likewise, the traditional working practices of Ethiopian public organizations criticized as being fragmented across various units of the organization and each unit focused only on one task that leads to frustrate the customers from ups and downs to get services from various units handoffs.

Supporting this, other author reported that Ethiopian institutions criticized for their poor service delivery systems. Thus, in this ever changing and competitive environment the traditional working practices of Ethiopian public organization are not efficient, effective and economical [3].

To alleviate like the above-mentioned working practices, recently, the former Ethiopian Ministry of Capacity Building tried to introduce transformation in Ethiopia in which works have to be done by all governmental organization through BPR. Accordingly, under the delegation of MoE, Ethiopian public universities engaged with BPR project to drastically change the traditional working practices.

To commence reform initiatives, all public universities have identified their problems. For instance, Addis Ababa University BPR initiative report stated that the University losing its grip on a clear sense of direction and performing below all expectations and its full potential [4]. In addition, Mekelle University BPR report stated that the University faced many problems due to limitation in its current organization setup and systems of operation [5].

However, all universities not yet fully implemented the redesigned processes. Supporting this, Debela and Hagos claimed the existence of BPR implementation pace variation in Ethiopian higher education [6].

According to Debela and Hagos, BPR implementation in Ethiopian public organizations accompanied by doubt, skepticism, and fear of losing the status quo. With respect to Ethiopian public universities, BPR implementation challenges traced to various factors that were identified by different authors [7]-[11], such as change management, management competency and support, organizational culture, project planning and management, IT and financial resources.

Naod in his work also identified the major challenges of Ethiopian public universities in the implementation of reform initiatives; such as, lack of creating organizational culture and values for change and problems related to rigid hierarchical structure, job definition, and responsibility allocation, absence of incentive, training and education, lack of necessary changes in human resource policies, and lack of leadership, commitment and support by 
senior management [12].

The roles of leadership are crucial in the management of transformational change in higher education [13] [14] [16]. Leadership creates an environment conducive to a culture of tolerance and understanding, effective strategic planning and shared decision-making in a variety of strategic issues [17]-[25].

On the other hand, the restructuring of the higher education institutions has posed leadership challenges, which is determining and leading institutional strategies for change, viability, and excellence while committing to relevance to local and national needs [14] [15].

Saint, and Teshome assert that the major challenges and problems of the higher education sector in developing countries are: 1) lack of clarity in vision and mission, 2) problems of quality and relevance of programs of studies and research, 3) lack of clear program and institutional evaluation mechanisms, 4) lack of commitment of the leadership of the sector at all levels, 5) centralized internal governance and weak management system, 6) weak consensus building efforts and participation of stakeholders [1] [26].

Institutional capacity, particularly in relation to human resource development, remains a major obstacle to reform in Ethiopia [27]. Chanie makes the point that for the reforms to succeed, vital preconditions remain absent in Ethiopia including: Absence of well developed bureaucratic structures with competent personnel, lack of proper governance environment, lack of participation by key stakeholders, absence of strong institutional framework [29].

The conditions of modern institutions functioning require undertaking some radical, transformational changes [29]. Management of such changes, however, requires some new management qualities. One of these qualities is transformational leadership. However, in the institution under study, though transformative kind of change has been introduced, the leaders lack qualities of transformational leadership. Obviously, a change at WSU, as I experienced and obtained from Annual performance reports of the University characterized by less sense of ownership of the implementer, less commitment and resistance to the change.

Concomitantly, the attempt to introduce the change to the University community was less and taken as a formality. This, as annual performance report of the WSU argues results in failure to understand the essence and purpose of the change. This has been observed when academic leaders at faculty, school and department level seek approval of the top officials before making a decision, even on issues under their discretionary. Other than anecdotal complaints heard from faculty about incapacity of leaders to manage the sought transformation, no systematic study has been conducted.

Therefore, in light of the above perspectives, this study intended to investigate the staff perception towards leadership in transforming Wolaita Sodo University. To meet its purpose the study guided by the following research questions

1) What are the perception of staff towards transformation \& leadership in transforming Wolaita Sodo University?

2) To what extent does transformational change prevail at Wolaita Sodo University?

3) To what extent academic leaders exhibit transformational leadership behaviors at Wolaita Sodo University?

4) What major challenges encountering in the transformative change process at Wolaita Sodo University?

\section{Review of Related Literature}

\subsection{Transformation and Change in Higher Education: Concept and Nature}

Why and how higher education institutions transformation and change has been one of the major concerns of higher education scholars [30]-[32]? Higher education institutions are characterized as value-driven institutions, loosely coupled systems, inhabiting multiple power and authority structures, complex decision-making structure, and relatively independent of the environment they exist in [33]-[38]. Considering these qualities of higher education institutions, some authors (e.g. [31] [36] [39] [40]) argued that change in higher education institutions is likely to be a slow, political, and challenging process. Hence, it needs transformation.

There are forces that lead to transformation and changes of higher education institutions. Different scholars (e.g., [41]-[43]) emphasize the following forces of change in HEIs: the effects of the expansion of higher education and the push for greater access; declining resources and the challenge of diversifying funding resources; the conflict surrounding institutional autonomy; the growth of technology; and the drive for internationalization of HEIs. Another perspective on the change process gives due attention to the actors involved: government, faculty members, governing boards, students, and institutional leaders, and stakeholders [44]. Above all, the role of the insti- 
tutional leaders depends largely on the relative importance and clout of the other actors involved in the change process [45].

Thus, the topic of transformational change in higher education has become increasingly prevalent over recent years [46]. The reasons are many, including daunting fiscal and demographic challenges, institutional opportunities presented by new technologies; the growth of learning industry; increased competition for faculty and students; higher expectations and changing demands from a wide and diverse group of stakeholders [47]. Mankind appears to be locked in an ambivalent relationship with change. Despite clear resistance to the unsettling result of change [48] [49], the desire for change characterizes much of human endeavor, and has done so since the dawn of consciousness. Owen in [50] describes transformation as the organizational search for a better way to be. In fact, Owen argues that it is when the environment alters in such a way that the old way of doing business is no longer or possible, that a new way becomes essential to survive. The central idea of the word transformation is movement across or through forms and [45] [50]) states the following in this regard:

"Transformation is a process of transmutation of one form in to another. In the educational places, which refers, in part, to changes in the knowledge and abilities of students, the development of domain of ability?"

Transformation and change are not synonymous processes [50]. In this view transformation is a pre-condition for change to take place. Table 1 shows a comparison of these processes and explains the differences.

Another writer, Kelli summarizes the distinction between transformation and change as follows: transformation is the function of altering our being, that is, of creating something that is not possible in our reality; change is a function of altering what we are doing, that is, of improving something that is already possible in our reality [51]. Therefore, 1) transformation is either a process or a state; 2) transformation can be change in either a compositional/structural or clear sense.

\subsection{Organization as Systems of Change}

Most of the time, people look for an organization independently from its system and components but this is fallacy. An organization is a complete functioning unit made up of integrated systems that allow it to run to carry out its purposes or goals. The separate subsystems of an organization include the social system, the technical or working system, and the administrative system [52].

Systems are, first, integrated wholes whose specific structures and identity derives from the interactions and interdependence of their constituent or parts [53]. Systems thinking emphasize processes and dynamic ongoing relationships and not isolated elements [52]. From this perspective, organizational change requires an understanding of, and intervention in, the wider context of what [54] [55] refer to as a system [56] support this by saying: "institutions no longer have a choice they must change to survive" (1998: p. 138).

What Old calls whole system organizational change' occurs on three levels: transactional (observable ongoing work), systemic (strategy, structure, culture, rewards, technology, information), and deep structure (underlying patterns) [57]. She argues that well-integrated change method and system is needed if organizations are to respond well to change and implant new thinking and a change orientation in the organization's deeper systems and interactions.

The changes in workforces with a greater degree of demographic diversity, technological change, and increased international competition, which will place new demands on the leaders of tomorrow. Leadership as a change management process focused by fact that change, by definition, requires a new system and then institutionalizing the new approaches [58].

Producing change is the primary function of leadership [59]. Important, according to [58] is that leaders must adopt a new perspective to lead the changes required to build world competitive organizations. He adds that or-

\section{Table 1. The difference between transformation and change.}

\begin{tabular}{lll}
\hline \multicolumn{1}{c}{ Change } & \\
\hline - A physical process & - Demands a process-involves human beings \\
- Simple & $\bullet$ Complex \\
- Time specific & $\bullet$ Takes time-usually more than we expect \\
- Happens externally to the human being & $\bullet$ Requires exceptional skills and reorientation \\
- Embodied in policy & $\bullet$ Does not have a final script \\
\hline
\end{tabular}

Source: Raubenheimer, 1996, p. 228. 
ganizations are first social systems, secondly economic enterprises, and that action-orientated, value-driven, supportive leadership is at the center of every organization to give the driving force for change. But because of lack of new perspective to lead change in the organization, institutional transformation become unsuccessful [59].

Organizational change fails because of many factors. But most importantly, Kotter, believes that organizational change typically fails because senior management commits one or more fundamental errors. He recommends that organizations should follow eight sequential steps to overcome these problems: 1) establish a sense of urgency, create the guiding coalition, 2) develop a vision and strategy, 3) communicate the change vision, 4) empower broad-based action, 5) generate short-term wins, 6) consolidate gains, 7) produce more change, and 8) anchor new approaches in the culture.

\subsection{Leadership for Transformation and Change in Higher Education Institutions}

To meet follower performance and transform the institutions beyond the ordinary limits, leadership must be transformational [60]. Followers' attitude, beliefs, motives, and confidence need to be transformed from a lower to a higher plane of arousal and maturity [61].

Transformational leadership is a new model of leadership that attracts scholars' attention [62]. The concepts of transformational leadership is among the most popular and current approaches to understanding leader effectiveness [63] [64], and developed as a new model of leadership [60] [65].

The goal of transformational leadership is to "transform" people and organizations in a literal sense-to change them in mind and heart; enlarge vision, insight, and understanding; clarify purposes; make behavior congruent with beliefs, principles, or values; and bring about changes that are permanent, self-perpetuating, and momentum building [65].

Transformational leadership describes the process of constructing commitment to the organization's goals and making followers more confident to make these goals [61] [66]-[69]. As a result, traditional leaders: use their personal values, vision, commitment to a mission, and passion to energize and move others towards accomplishment of organizational goals [70]; help to map new directions [71]; mobilize resources, ease and support employees, and respond to organizational challenge [72]; consider change when it is necessary for the organization; act as agents of change [73].

The creative, imaginative, empathetic, and risk-taking leader is the centre of the transformation process that fosters organizational viability [74]. The process by which transformational leaders move large organizations through major change and found that these leaders move through three phases as studied by [74]. Firstly, the transformational leader recognizes the need for change and persuades key people in the organization of the seriousness of this need. Secondly, the leader involves key people in the development of an inspiring vision of the future. Finally, he or she mobilizes commitment to the new vision. Thus, according to these researchers, organizational transformation occurs in three steps: 1) recognizing the need for revitalization, 2) creating a new vision, and 3) institutionalizing change [74].

Similarly, [75] outline three slightly different steps to transformation: 1) create a new and compelling vision, 2) develop commitment for the new vision, and 3) institutionalize the new vision. Both groups of researchers contend that transformation involves changing the values of members to support an important, compelling, and rewarding vision that encompasses the members' needs and values.

Institutional leaders are expected to play pivotal role to make the process of change faster in academic departments [76]-[79]. In order to materialize their mission, however, higher education institutions need proactive leaders and satisfied staff [80]-[82].

Therefore, higher education leaders should select effective leadership style to direct their institutions toward success. Transformational leadership is one of the integrative leadership theories to which directing effective organizational change [61] [83]-[86].

\subsection{Challenges of Higher Education Leaders under Transformation Process}

Transformational leaders have to take the HEIs to which they are assigned from their present situation to some future condition that would bring about the expected change. This, however, brings about various transformational challenges. Failure of transformational leaders to build trust among their followers is one of the challenges widely mentioned [51] [87].

The more people trust their leader, and each other, the more they take risks, make changes and keep organiza- 
tions and movements alive [51]. As righty noted by Kelli, "change often begins in trust” (p. 132), lack of trust, resistance to change, resources constraints, lack of employee commitment and poor management and leadership strategies are serious challenges in transformation process as [88].

Thus, above all, institutional leaders should give high emphasis to trust their staff by creating an environment based on communication, collaboration, inspiration, and integrity to comprehend the desired change in the institutions.

\subsection{Conceptual Framework ${ }^{1}$ of Transformational Leadership Behaviors}

Figure 1 shows the conceptual framework of transformational leadership. This study is based on conceptualization of the Kouzes and Posner's leadership model and other added vital components to realize transformation process. Their research, suggested that leadership is not a place, but a collection of practices, which are essential components of the concept of transformational leadership. They developed through intensive research on current leadership practices and recognized by many researchers as truly representative of highly effective leadership practices [89]. These practices are: challenging the process, inspiring a shared vision, enabling others to act, modeling the way, and encouraging the heart [90] [91]. But to properly realize the practices there need to be some sort of ingredients ${ }^{2}$. These ingredients are highly crucial to properly display the desired leadership practices. In the following sections, the practices and their ingredients discussed in detail.

\subsubsection{Leadership Practices}

Challenging the Process: Is a way of life for transformational leaders. By either creating new ideas or recognizing and supporting new ideas, leaders show willingness to challenge the system in order to turn these ideas into actions and to get new products, processes, and services adopted, seek out challenging opportunities that test their skills and abilities and look for creative ways to improve their organizations, willing to change the things as they are, experiment and take risks with new approach, learning for them is a lifelong behavior. In order to succeed, it needs leaders' focused approach to make mistakes because every false step opens the door to a new opportunity, instead of punishing failure; they encourage it because they learn from each.

Inspiring a Shared Vision: Is vital for bringing people in any organization together to foster a commitment to a shared future they seek to create. Transformational leaders passionately believe that they can bring changes by envisioning the future and creating an ideal and unique reputation of what the organization can become, inspire such a vision in their followers with a positive and hopeful outlook, generate enthusiasm and excitement for the common vision from others through genuineness and skillful use of metaphors, symbols, positive language, and personal energy.

Enabling Others to Act: Is fostering collaboration and empowerment, involve others in planning and give them freedom of choice in the decision-making process, allows followers to do their job and to realize their full potential, strive to create an atmosphere of trust and human dignity, to help each person feel capable and powerful, consider the needs and interests of others and let them feel as if they carry ownership and responsibility in the organization.

Modeling the Way: Means specifically leaders go first, set an example and build commitment through daily acts that create progress and momentum, create a program of excellence and then set the example for others to follow, need to have a philosophy, a set of high standards by which the organization evaluated and a set of principles about the way people treated and the way goals pursued that change the organization unique and distinctive, show by example that they live by the values they advocate.

Encouraging the Heart: People often need encouragement and motivation to do the goals set by the organization. Successful leaders have high expectations for themselves and their employees, their credibility is based on

\footnotetext{
${ }^{1}$ [92] has described a conceptual framework as “a skeletal structure of justification, rather than a skeletal structure of explanation” (p. 210; italics added). A conceptual framework is an argument that the concepts chosen for investigation, and any anticipated relationships among them, will be appropriate and useful given the research problem under investigation. Like theoretical frameworks, conceptual frameworks are based on previous research, but conceptual frameworks are built from an array of current and possibly far-ranging sources. The framework used may be based on different theories and various aspects of practitioner knowledge, depending on what the researcher can argue will be relevant and important to address about a research problem.

${ }^{2}$ Ingredients are additional components which are vital to speed up and comprehended the transformation process of the institution so as to attend the intended goals of the organization. With the absence of these ingredients, it is impossible to realize transformation process of the organization. Thus, ingredients are not considered under the Kouzes and Posner 1995, 2002 models but now modified with the inclusion of those ingredients.
} 


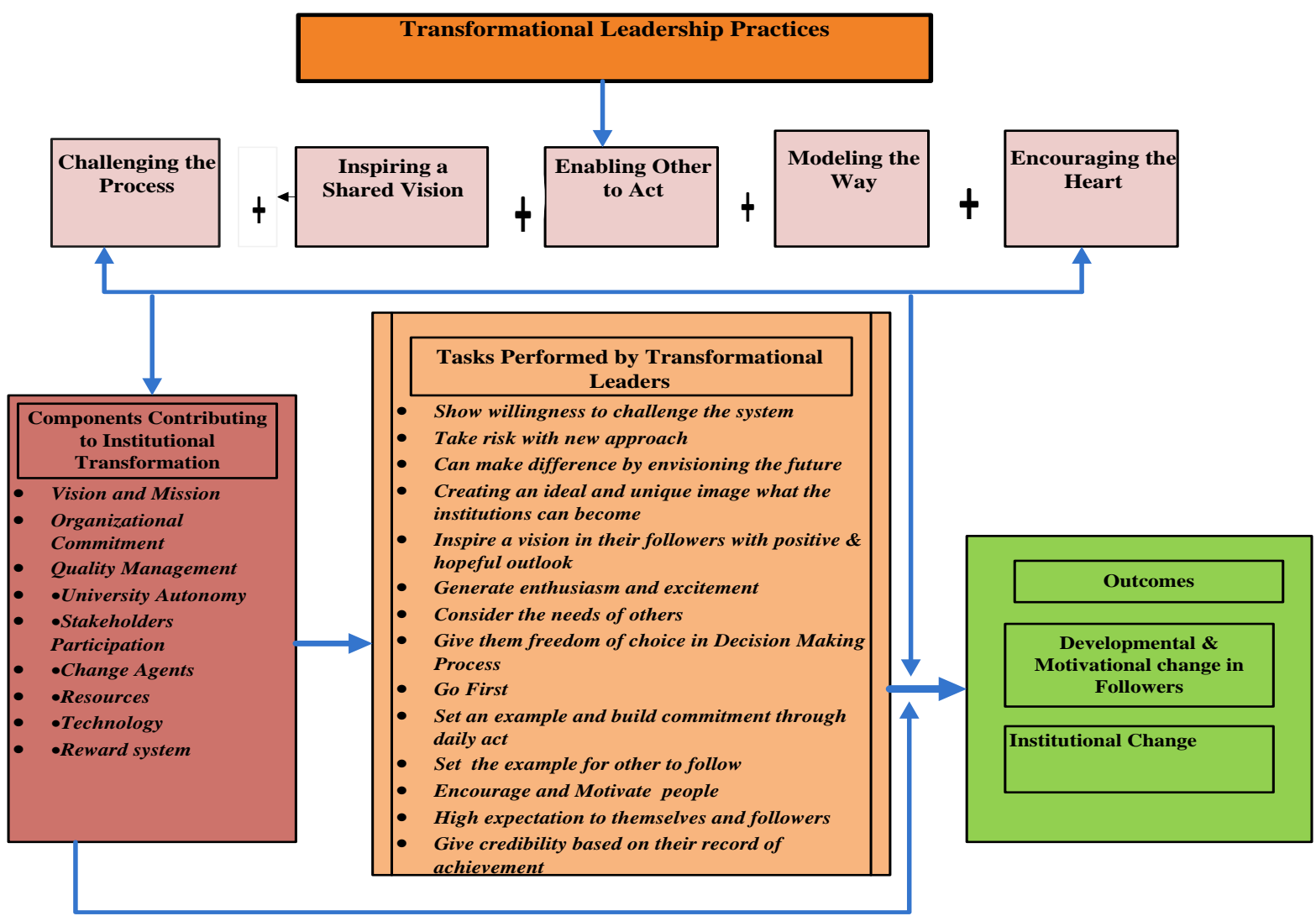

Figure 1. Kouze's and Posner's model in transformational leadership—2002, 2008, modified in 2014. Source: Kouzes and Posner's model—2008, p. 650, modified—2014 by Mulatu D. Lerra.

their record of achievements, dedication, and daily demonstrations of what and how things need to be done, by influencing employee motivation, leaders attach rewards and recognition to job performance, play a special role in the celebrating of person or group achievements, because they are the most prominent personality in the organization and serve as role models. When leaders urge their employees through recognition and celebration, they inspire them to do better.

\subsubsection{Others Ingredients Contributing to Institutional Transformation}

Vision and Mission: The vision statement describes the way one wants the institution to be in the future. The organization's vision includes: clarification of the organization's values; agreement on the basic beliefs that guide the organization; exploring what ideas and trends could change the way the sector is doing business; identifying what needs are emerging as a result of demographic, technological, economical, political and regulatory trends; identifying who is needed to make the vision possible [93].

The mission statement provides the purpose or reasons for the institution's existence, expresses philosophy, community service, research or educational commitments, affiliations and major functions or services offered by the institution [93]. The mission statement should be a specific, concise articulation of what the government wishes the sector to be and establishes the guiding principles from which the transformation process flows and is unique to your institution. Hence, transformational leaders are expected to have clear vision and mission in order to meet the intended outcomes of the institution.

Quality Management (QM): Effective higher education system is pivotal in creating strong human resources that advance the future of nations. This system should include quality management as a first step in the creation of a strong organization that targets satisfying various stakeholders, such as students and parents, communities, public and private sectors among others. A system considers QM as a main cause that shapes the strategies towards better higher educational institutions with a better satisfaction level [94]. 
Researchers argue that organizations are not merely technical systems because they also have human systems [94]. Hence, transformational leaders give due emphasis to the quality management of the institution to mobilize and use the resources in a proper way to transforming the University in to an intended place.

Resources: Are defined broadly to include knowledge, technology, power, material, people, time assessment, data and finance [95]. Transformational leaders should orchestrate all the necessary elements which clout the implementation of transformation process.

Change Agent: New structures, work methods, and performance goals, all must adjustments in the way change agents behave. Change agents can have powerful effects on members' behaviors, beliefs, and values and can influence members' performance levels, task methods, and work relationships [96]-[98]. Having proactive change agent in transforming organizational changes can help to assure commitment to implementing them [99]-[101].

Reward System: Another useful means for helping employees bring their goals in close harmony with those of the organization is the use reward. The purpose of rewards is to increase the chance that work assignment will be accomplished through employee acceptance and commitment, and concurrently meet the transformational plan of the institution [102].

Information Communication Technology: It is clear that information communication technology (ICT) has changed all aspects of man's living. The ways that different professions work has been dramatically changed over the past three decades [103]. The influence of ICT is considered as immense on education especially, in transforming the institution and shaping the ways of delivery [103]. Many educators believe that ICT creates flexible and virtual learning environment that can attract large number of students with different background, offer opportunity to improve educational quality, support contact between instructors and students at different site, and enable Universities to be in a good place in education market.

Organizational Commitment: Is considered as a useful measure of organizational effectiveness [104] [105]. In particular, a multidimensional construct has the potential to predict organizational outcomes such as performance, turnover, absenteeism, tenure, and organizational goals [106]. Scholars [107] examined the relationships between the broad construct of organizational commitment and the outcome measures of leadership trust, job involvement, and job satisfaction. In all three areas, [108] reported positive relationships with organizational commitment. More specifically, perceived trust in the leadership, an ability to be involved with the job, and feelings of job satisfaction were major determinants of organizational commitment.

University Autonomy: Is defined as "the freedom of an institution to run its own affairs without direction or influence from any level of government” ([109], p. 123). University autonomy was introduced as a strategy so that Universities become more efficient and effective and it allows Universities to appoint faculty and staff without external influences; enable them to decide about admission criteria and number of students to admit, allowed them to decide about the contents of the curriculum and teaching methods, and enabled them to prove their own priorities for Universities' future growth and development [110]. According to some authors [111] [112], institutional autonomy is a much debated concept and carries different meanings in different contexts and thus may hold different dimensions. Mostly it denotes the managerial ability of an institution to set its own goals and priorities, and determining its own means and set of standards to make these goals without external influences.

\section{Research Design and Methodology}

I opted for case study research method to this qualitative research design was because I wanted to do an in-depth study of a single organization. As to [113] [114], qualitative research is better way to dig views and perception of participants in a natural setting. Similarly, case study approach attempts to convey a balanced, multidimensional representation of the context, participants, and reality of the situation and allows investigators to keep the holistic and meaningful characteristics of real-life events very important to answer "how" and "why" questions [115][117].

Accordingly, Wolaita Sodo University is considered as a case study area for the research under concern mainly for the following reasons, the non-existence and/or limited empirical studies, seriousness of the problem, the researcher practical experiences about the University.

\subsection{Target Population and Research Participants}

This is a case study done on a single organization and for this purpose I selected Wolaita Sodo University as a unit of analysis. A sample of 5 academic and 5 supportive staff for FGDs, 2 college deans, 1 director, 2 department 
heads for interview took part in the study. Totally, this qualitative inquiry involved 15 participants.

\subsection{Sample and Sampling Technique}

The nature of the study required such kind of sampling from academic and supportive staff who are involved in the transformation process of the University. I started with the purposive sampling technique because data had to be gathered from all those who involved in transformation process of the University. Thus, it is said that when obtaining samples (occasionally called "judgment samples"), researchers use their subjective judgment and attempt to select sample units that a particular sampling units included in the sample primarily depends on the researcher's subjective judgment [118]-[120]. It is with this intent, purposive sampling technique was used to address the objectives of the study from purposively selected respondents

\subsection{Data Collection Instrument}

The tools used to gather relevant data from the research participants were key informant interviews, focus group discussion (FGD) and relevant document analysis. The objective of the interviews was to examine respondents' attitudes toward the transformation process of the University and was to look at the respondent's point of views and not make generalizations about behavior and to scrutinize respondents' attitudes toward the University leadership behaviors [121] [122]. Deans, department heads and director was part of interview. Focus group discussions (FGDs) was also used to explore details of data, to understand the workplace and get an insight into how people think and behave as well as work. FGDs are relatively quick, inexpensive; [114]. The academic teaching and supportive staff was part of FGDs. The strategic document of the University like growth and transformation plan (GTP), business process re-engineering (BPR), balanced score card (BSC), kaizen has also been used to evaluate the formal transformation process exist in the situations. Using documents as sources of data have two main advantages: 1) the data is "Non reactive”, 2) document exist independently of the researcher's activity [113]. The analyses of documents in social research give the researchers control to capture details of happenings in its real context [123].

The participants (Deans, Department heads, Director) were interviewed by the researcher and made discussions with FGDs (Academic teaching and administration staff) for average of 1:00 to 1:30 hours. All interviews and FGDs were recorded in detailed hand written notes, all of which were later compiled in to field notes. The data collected during the interviews was of qualitative and it was well documented as the data collected through quantitative means. The people interviewed were professionals, having the relevant designations and qualifications and had professional experiences, so their annotations expand and compensate large number of respondents.

\subsection{Procedures of Data Collection}

Firstly, review of literature made to assess theories and research reports on the issue under study to develop research questions, FGDs and interview guides. Then, choice of study participants was made by judgment and sampling to get relevant data. Following this, data gathered from the key informants; deans, department heads and academic and supportive staff, as well as director. Respondents interviewed on similar issues with different approaches.

During the course of interviews and FGDs, I allowed the respondents to fully express their views without any interruptions and remained very flexible with their approach. In case study method, the researcher should be very flexible with his/her approach to get the required data [124], but I redirected the respondents towards the topic, and made sure that all the dimensions of their study are fully covered. Considering the context and nature of the study, audio-recording device was not used to keep both the confidentiality and anonymity data given by respondents.

Two FGDs were made with academic teaching and administrative staff respondents to supplement the views expressed during the interview sessions for 1:30 hours to each. Because the very objective is to capture dynamic issues which corroborates information obtained through other methods as well as look into issues of similarities and differences.

\subsection{Data Analysis and Discussion}

Data analysis and discussion consists of following steps: Data preparation and data reduction and coding. 
Data Preparation: I jotted down all the necessary information from in-depth semi-structured interviews and FGDs. The next day, it was accompanied by interview and FGDs to completely capture the views of the respondents. For this purpose, I followed the strategy of conducting only one interview in a day and this helped to transcribe the interviews on the timely, thus, there was only minimal loss of data.

Data Reduction and Coding: During the exploration phase of the data analysis, I read the transcribed data repeatedly to highlight important areas and significant points, which was noted down in the form of memos. The important narratives were also identified and highlighted. Data reduction entails axial coding and it is types of coding which focus on thematic analysis or based on axes (transformation tools, transformation pill and indicators of change) and it helps to find different themes, categories and patterns that exist in the data [125] and it is also done in the exploration phase of information analysis.

Similar patterns and themes were identified in the transcribed interviews and FGDs, where contrasts/comparisons were made along themes. The most important narratives were identified and noted as evidences, which I quoted in places where needed. I also collected and reviewed institutional documents which, supported the data collected through interviews and FGDs. The key areas identified placed under the major themes. The data analyzed, and interpreted using these themes and categories, based on these themes conclusions were drawn from the findings.

\section{Major Findings}

\subsection{Demographic Characteristics of Participants}

Out of the 15 academic and supportive staff participants, 13 were males while the rest 2 were females. All academic leaders were male. Despite gender equality in terms of University leadership is work in progress, my study implies that almost all the University's leadership positions are occupied by men. On the other hand, while the majority, (10) academic and supportive staff were in the age group 30 - 40, the rest (5) aged 41 years and over. This shows that being in the working age group is an advantage for the University, because they will be willing to adapt ways of doing things towards institutional transformation. The interviews and FGDs results revealed that the greatest, (9) staff participants were master's degree holders and only 4 had a bachelor degree qualification. The rest (1) completed diploma level of education. In other words, the smallest academic qualification was diploma. Hence, as expected academic staff were better qualified than the supportive staff.

Out of the total participants, (3) of the respondents have less than five years of work experience, while majority, (12) of the participants fall within the range of 5 - 10 years of work experiences. The work experiences reveal that they can work hard towards institutional transformation process.

\subsection{Research Question 1: What Are the Perception of Staff towards Transformation \& Leadership in Transforming Wolaita Sodo University?}

In order to check perception of the participants towards their leadership under transformation process, each respondent was asked to share his/her views on the concept of transformation. The findings obtained from respondents presented as follows:

Despite the respondents work in the same institutions towards similar organizational goals, they have varied views on the concept of transformation. For instance, some put forward transformation as "... a new way of institutional change agent towards the desired goals 'while, some other see it'... as an approach being introduced into institutional set up to enhance the capacity of leaders towards the preset objectives". However, a common point to the respondents is that it is viewed as "... a process of change from an old way of doing... to new and modern one". Hence, lesson learned from such conceptualization is that much need to be worked towards proper understanding of transformation among staff and work towards the success of institutional goals with similar level of understanding.

Furthermore, for effective implementation of transformative change in HEIs, adequate knowledge of a change agent about the context of the institution under transformation is very important [126]. It should therefore, deal with changing people and the system. But the results obtained reveals that the efforts of top leaders made to introduce the change to the academic and supportive staff was less, or not adequate as confirmed by both academic and supportive staff participants. 


\subsection{Basic Question 2. To What Extent Does Transformational Change Prevail at Wolaita Sodo University?}

To answer this research question, KIs were interviewed, FGDs made and reviewed various documents (reports, bulletins and achievement reports) of the University.

Old states that a well-integrated change methodology is needed if organizations are to respond well to change [57]. But the research results from KIIs, FGDs, and relevant documents portrays that despite transformational change observed in the University compound, the expected change is not yet metalized. This is manifested in the before and after transformation scenarios described in the below.

Initial Situation (Before Transformation): In the University, the annual performance results reports reveal that there is very limited internet access, no ICT center, no LAN existed, No E-teaching and learning lab, highly decentralized student administration, limited staff upgrading, limited scientific publications, limited industry linkage, no facility of system maintenance, few academic curriculum revision, limited opening hours of library service are some of the situations before the transformation process.

After Transformation: The situations after transformation process reveal that there is good internet access but not satisfactory, wired and wireless LAN existed, ICT center established, systematic and preventive maintenance and repair established but not functioning well, no E-teaching and learning lab, pedagogical skill improvement and support center established but not well equipped, centralized enrollment and examination department established but not functioning well, good staff upgrading particularly academic teaching staff, many scientific journal publications, still limited collaboration and partnership agreements with industries, no International office established to support international exchange, good library service. Source: Adapted from Document Analysis (February 06, 2014).

\subsection{Basic Question 3. To What Extent Leaders Exhibit Transformational Leadership Behaviors at Wolaita Sodo University?}

Under this part I discovered the level of transformational leadership behaviors that University leaders show during their administrative practices on daily basis. The findings presented as follows:

For example, KIIS, FGDs, and interviews made both with academic staff confirmed as to how leaders reactants is holding the institutional transformation process as:

Even though academic staff work their level best to see the institution stand on its feet senior sister organizations, fewer attention and reluctance from the top officials held the organization progress as slow as... the journey if tortoise. This case is mean to illustrate the exerted efforts of the academic staff towards organizational transformation process under bureaucratic and less willing top officials system of governance. Similarly, one of the woman from academic teaching staff in FGDs claimed that "leaders always unenthusiastic to take risk. With the same token, one of the lecturer from FGDs stated that, the level of readiness of the University leaders to learn new and challenging idea is not encouraging, (L1).

However, paradoxically the director from key informant interview stated, "the University leaders did all their best potential to engage academic staff in research and community services, what matter is the amount of money allocated centrally from Ministry of Finance \& Economic Development (Dr1)”. As seen here, the level of readiness and politeness of the top University leaders to their academic and supportive staff is insufficient to comprehend the institutional transformation.

The other transformational leadership behavior is inspiring a shared vision. In this sense both KIIs and FGDs, participants remarked,

Dean: The University leaders to create enthusiasm among staff are not satisfactory as expected. Other dean from KIIs claimed, both staff as well as the leaders have less commitment to their organization, but few smart staff who are highly committed for their University betterment. Paradoxically there are teaching staffs who are not committed to achieve the vision and mission of the institute (D1).

The Director from KIIs stated,

Director: The president is highly committed to create collaborative working environment, but all the leaders under his supervision are not equally dedicated to make the working environment very smooth and conducive. He also states that both academic and supportive staff are pessimistic about the system functionality of the 
University (Dr1).

As can be understood from the participants response, to set high academic standards and motivate people towards transformation process, the level of commitment of top leaders to generate enthusiasm and excitement for their common vision is not satisfactory.

With regards to enabling others to act behavior, both colleges deans except the director asserted,

One of the failures of leaders is low level of empowerment of the middle and first line managers who are highly engaged in operationalzing transformation process. Dean $1 \& 2$. Dean: Similarly, as department head $1 \& 2$, they are averse to consider the interest and needs of others, lack of trust on their followers. One of the dean remarked, the level of respect to academic professionals including expatriates is insufficient. Both administration and academic wings are not working properly on this respect (D1).

One can say that the leaders do not thoughtful to deal with their followers and their professional needs, there is no trust between staff and their leaders. As seen, the top leaders do not respect the staff and even expatriates and they want to use power against them. It gives the impression that University leaders failed to display enabling others to act behaviors in their daily activity.

One of the dean stated, "The level of University leaders commitment to encourage their employees through recognition, reward, celebration, and inspiring them to do better is not sufficient (D1).

As important to Mulatu (2013), encouragement is curiously, serious business. It's how leaders visibly and behaviorally link rewards with performance. Despite University leaders tried to encouraging and motivating the academic staff to some extent, the results reveals that still there is a yawning gaps. Hence, I can infer that the types of transformational leadership behaviors were not satisfactorily exhibited in the University.

\subsection{Basic Question 4. What Major Challenges Are Encountering in the Transformative Change Process at Wolaita Sodo University?}

To find out the nature of challenges experienced by University leadership which are associated with transformation process of the respective University, the views of deans, department heads, academic teaching and administration staff and director were sought.

In identifying the major challenges in implementation efforts both groups of respondents agreed on lack of clear understanding of transformation process; less awareness of all staff members; less commitment in all levels; shortage of resources; lack of team spirit, integrity and collaboration across and among faculties, schools, departments; resistance to change; poor leadership and management; lack of academic freedom; less commitment of the University leadership to build trust among followers; lack of departmental and faculties/schools autonomy; lack of reward system and clear promotion as perceived by all study participants of the institution commonly.

\section{Concluding Remarks and Ways Forwarded}

\subsection{Concluding Remarks}

On the basis of the description, analysis, interpretation of data made and results obtained, the following conclusion was drawn. Based on the discussion made and major findings obtained, I could arrive at the flowing conclusions.

Any transformational change has to focus on the where to where of the organization. Despite the positive attitude of the participants towards transformation process, the finding, however, shows that the effort to introduce the changes towards the lower administrative unit and motivate the staff for better organizational transformation process remained questionable. On the other hand, structural and technological transformation was exhibited as the major areas of changes in the case study area. However, transformational leadership behaviors exhibited by academic leaders can be labeled as minimal.

Less attention in building trust-ship among University community by top officials, lack of resources, lack of commitment, team spirit and collaboration among implementer were identified as the major bottlenecks for institutional transformation process in the study area. It is said that staff perception towards University leadership behaviors is not satisfactorily displayed as the studied groups. Therefore, due to inadequate introduction and awareness of the staff for the change, inadequate transformational qualities of the leaders, structure oriented concern of the change and the challenges identified, it is safe to infer that the change at Wolaita Sodo University lacks transformational dimension and hence the change may not meet its intended goals. 


\subsection{Ways Forwarded}

Based on the study results, discussions made and conclusions drawn the following workable recommendations were put forwarded.

For effective implementation of any change, attempting better understanding of the implementer about the essence of the change is very essential. Regarding this, [126] [127] stated that, it is not easy to change something in an effective way if there is no understanding of what it is that is changing. However, the study revealed lack of understanding of the change implementer about what is changing. Therefore, continuous awareness creation activities should be made by top academic leaders at the various levels on the essence and goals of the transformation and change.

Transformational change is a process where an organization changes in its form, structure and culture to adapt to environmental changes [126]. It is a fundamental change that requires exhibiting effective transformational leadership behaviors. However, the study results showed that the academic leaders less practice transformational leadership qualities. Therefore, the leaders should be aware of transformational leadership qualities and show the behaviors so. Leaders should in turn need to be transformed to exhibit the behaviors in this respect. In any change process leaders are expected to build trust among followers. Regarding this, Kelli, contends that, change often begins in trust. However, lack of trust, resisting change, lack of team spirit, poor leadership/management qualities, resources shortage, lack of autonomy, reward and promotion, lack of commitment, and dedication were identified as some of the major challenges to the change process. Therefore, the University leadership should build trust, team spirit, integrity and share its autonomy to faculties and schools and department as well as supportive staff, and they should be committed to change.

Transformational change in higher education focuses on changing people, structure and technological aspects of an institution. However, results of the study showed that the transformational change process of the institution gave much emphasis towards changing organizational structure. Therefore, the transformation should primarily focus staff empowerment on all levels of administration. The transformational leaders should focus on strategic issues instead of wasting time in changing and re-changing structures.

Concomitantly, change implementer should be committed. To this effect their roles and responsibilities should be clearly specified, which calls for the adoption full decentralization processes at the study area. The realization of transformational goals requires mobilization of all the necessary resources including human and non-human. But, the study revealed that lack of resources as one of the challenges that meet the transformational change process. Hence, the University should diversify its sources of income instead of relying on government subsidy and should be autonomous to run its own affairs without direction or influence from any level of government.

\section{References}

[1] Yizengaw, T. (2003) Transformations in Higher Education: Experiences with and Expansion in Ethiopian Higher Education System. Keynote Paper Prepared for a Regional Training Conference on Improving Tertiary Education in Sub-Saharan Africa: Things That Work!

[2] UNESCO (1998) Higher Education in the Twenty First Century: Vision and Action. Frame Work for Priority Action for Change and Development in Higher Education. World Conference on Higher Education, Paris, 5-9 October 1998, 32.

[3] Desta, D. (2004) Observation and Reflection of the Higher Education Teachers on the Quality of Teaching and Learning in Ethiopia. The Ethiopian Journal of Higher Education, 1, 36-81.

[4] Addis Ababa University (2009) Business Process Re-engineering (BPR) of Addis Ababa University. Addis Ababa. http://www.aau.edu.et/AAUBPR\%20TOBE/AAU_BPR_Summary_Report_Draft.pdf

[5] Mekelle University (2008) Business Process Re-Engineering /BPR/, Academic Core Process Re-Engineering (ACPR). Mekelle.

[6] Debela, T. (2009) Business Process Reengineering in Ethiopian Public Organizations: The Relationship between Theory and Practice. Journal of Public Management and Development, 1, 20-59. http://www.ajol.info/index.php/jbas/article/viewFile/57348/45731

[7] Grover, V., Jeong, S., Kettinger, W. and Teng, J. (1995) The Implementation of Business Process Reengineering. Journal of Management Information Systems, 12, 109-144. http://www.jstor.org/stable/pdfplus/40398155.pdf?acceptTC=true

[8] Attaran, M. and Wood, G. (1999) How to Succeed at Reengineering. Journal of Management Decision, 37, $752-757$. 
http://www.emeraldinsight.com/journals.htm?issn=00251747\&volume=37\&issue=10\&articleid=85108\&how=pdf

[9] Allen, D. and Fifield, N. (1999) Re-Engineering Change in Higher Education. Information Research, 4, 251-289. http://informationr.net/ir/4-3/paper56.html

[10] Al-Mashari, M. and Zairi, M. (1999) BPR Implementation Process: An Analysis of Key Success and Failure Factors. Business Process Management Journal, 5, 87-112. http://dx.doi.org/10.1108/14637159910249108

[11] Ahmad, H., Francis, A. and Zairi, M. (2007) Business Process Reengineering: Critical Success Factors in Higher Education. Business Process Management Journal, 13, 451-469. http://dx.doi.org/10.1108/14637150710752344

[12] Naod (2011) Prospects and Challenges to Implement Business Process Reengineering (BPR) in Ethiopian Public Universities. Addis Ababa University, Addis Ababa.

[13] Dubrin, A.J. (2007) Leadership Research: Findings, Practice, and Skills. 5th Edition, Houghton Mifflin Company, Boston.

[14] Murphy, S.E. and Ensher, E.A. (2008) A Qualitative Analysis of Charismatic Leadership in Creative Terms: The Case of Television Directors. The Leadership Quarterly, 19, 335-352. http://dx.doi.org/10.1016/j.leaqua.2008.03.006

[15] RSA Doe, Republic of South Africa Department of Education (2002) Transformation and Reconstruction of the Higher Education System. Pretoria.

[16] Sarros, J.C. and Santora, J.C. (2001) The Transformational-Transactional Leadership Model in Practice. Leadership \& Organization Development Journal, 22, 383-394. http://dx.doi.org/10.1108/01437730110410107

[17] Bommer, H.W., Rubin, R.S. and Baldwin, T.T. (2004) Setting the Stage for Effective Leadership: Antecedents of Transformational Leadership Behavior. The Leadership Quarterly, 15, 195-210. http://dx.doi.org/10.1016/j.leaqua.2004.02.012

[18] Certo, S.C. and Certo, S.T. (2006) Modern Management. 10th Edition, Pearson Education Inc., Upper Saddle River.

[19] Dessler, G. (2004) Management Principles and Practice for Tomorrow’s Leader. 3rd Edition, Pearson Education Inc., Upper Saddle River.

[20] Felf, J. and Schyns, B. (2004) Is Similarity in Leadership Related to Organizational Outcomes? The Case of Transformational Leadership. Journal of Leadership and Organizational Studies, 10, 92-102. http://dx.doi.org/10.1177/107179190401000407

[21] Hoy, W.K. and Miskel, C.G. (2001) Educational Administration, Theory, Research and Practices. 6th Edition, Mcgraw Hall, New York.

[22] Riaz, A. and Haider, M.H. (2010) Role of Transformational and Transactional Leadership on Job Satisfaction and Career Satisfaction. Business and Economic Horizons, 1, 29-38. http://dx.doi.org/10.15208/beh.2010.05

[23] Tickle, E.L., Brownlee, J. and Nailon, D. (2005) Personal Epistemological Beliefs and Transformational Leadership Behaviours. Journal of Management Development, 24, 706-719. http://dx.doi.org/10.1108/02621710510613735

[24] Yukl, G. (1998) Managerial Leadership: A Review of Theory and Research. Journal of Management, 15, $251-289$. http://dx.doi.org/10.1177/014920638901500207

[25] Zaccaro, S.J. and Klimoski, R.J. (2001) The Nature of Organization Leadership. Jossey-Bass, San Francisco.

[26] Saint, W. (2004) Higher Education in Ethiopia: The Vision and Its Challenges. Journal of Higher Education in Africa, 2, 83-113.

[27] Mengistu, B. and Vogel, E. (2006) Bureaucratic Neutrality among Competing Bureaucratic Values in an Ethnic Federalism: The Case of Ethiopia. Public Administration Review, 66, 205-216. http://dx.doi.org/10.1111/j.1540-6210.2006.00573.x

[28] Chanie, P. (2001) The Challenges of the Civil Service Reform in Ethiopia: Initial Observations. Merit: A Quarterly Bulletin of the Ethiopian Civil Service Commission, 3, 26-29.

[29] Ivana, S. (1998) Transformational Leadership—The Key to Successful Management of Transformational Organizational Changes. University of Nis, Yugoslavia Economics and Organization Series, 1, 49-55.

[30] Clark, B.R. (1983) The Contradictions of Change in Academic Systems. Higher Education, 12, 101-116.

[31] Kezar, A.J. (2001) Understanding and Facilitating Organizational Change in the 21st Century: Recent Research and Conceptualization. ASHE-ERIC Higher Education Report, Jossev-Bass, San Francisco.

[32] Kezar, A. and Eckel, P. (2002) Examining Institutional Transformation Process: The Importance of Sense-Making, Interrelated Strategies, and Balance. Research in Higher Education, 43, 295-328. http://dx.doi.org/10.1023/A:1014889001242

[33] Armenakis, A.A. and Bedeian, A.G. (1999) Organizational Change: A Review of Theory and Research in the 1990s. Journal of Management, 25, 293-315. http://dx.doi.org/10.1177/014920639902500303 
[34] Bergquist, W.H. (1992) The Four Cultures of the Academy: Insights and Strategies for Improving Leadership in Collegiate Organizations. Jossey-Bass, San Francisco.

[35] Burke, W.W. and Litwin, G.H. (1992) A Causal Model of Organizational Performance and Change. Journal of Management, 18, 523-545.

[36] Porras, J.I. and Roberston, P.J. (1992) Organizational Development: Theory, Practice, Research. In: Dunnette, M.D. and Hough, L.M., Eds., Handbook of Industrial and Organizational Psychology, Consulting Psychologists Press, Palo Alto, 719-822.

[37] Van De Ven, A.H. and Poole, M.S. (1995) Explaining Development and Change in Organizations. Academy of Management Review, 20, 510-540. http://dx.doi.org/10.2307/258786

[38] Clark, B.R. (1998) Creating Entrepreneurial Universities: Organizational Pathways of Transformation. IUA Press \& Pergamon, Paris.

[39] Beer, M. and Nohria, N. (2000) Breaking the Code of Change. Harvard Business School Press, Boston.

[40] Clegg, C. and Walsh, S. (2004) Change Management: Time for a Change! European Journal of Work and Organizational Psychology, 13, 217-239.

[41] Ford, P. (1996) Managing Change in Higher Education: A Learning Environment Architecture. SRHE/Open University Press, Buckingham.

[42] Green, M.F. and Fischer, M. (1991) Transforming Higher Education: Views from Leaders around the World. Oryx Press, Phoenix.

[43] Kanter, R.M., Stein, B.A. and Jick, T.D. (1992) The Challenge of Organizational Change: How Companies Experience It and Leaders Guide It. The Free Press, New York.

[44] Clarke, M. and Meldrum, M. (1992) Creating Change from Below: Early Lessons for Agents of Change. Leadership \& Organizational Development Journal, 20, 70-82. http://dx.doi.org/10.1108/01437739910259172

[45] Strydom, A.H. (1998) To the Mark: Transformation of Change. CSD-UOFS Unit for Research into Higher Education. http://www.uovs.ac.za/bao/ishemain.html

[46] Yammarino, F.J., Spangled, W.D. and Bass, B.M. (1993) Transformational Leadership and Performance: A Longitudinal Investigation. Leadership Quarterly, 4, 81-102. http://dx.doi.org/10.1016/1048-9843(93)90005-E

[47] Zeffane, R. (1996) Dynamics of Strategic Change: Critical Issues in Fostering Positive Organizational Change. Leadership and Organizational Development Journal, 17, 36-43. http://dx.doi.org/10.1108/01437739610148376

[48] Gerard, E. (1994) The Skilled Helper: A Problem-Management Approach to Helping. Brooks/Cole, Pacific Grove.

[49] Senge, P.M. (1990) The Fifth Discipline: The Art and Practice of the Learning Organization. Doubleday Currency, New York

[50] Niekerk, D. (2005) Transformational Leadership at a Higher Education Institution. MA Thesis, University of South Africa.

[51] Kelli, M. (2010) Leadership in Higher Education: Handling Faculty Resistance to Technology through Strategic Planning. Online Journal of Academic Leadership, 8. http://www.academicleadership.org

[52] Dyer, W.G. and Dyer, W.G. (1986) Organizational Development: System Change or Culture Change. Worth Publisher, New York

[53] Pietersen, H.J. (1996) Organizational Change in Perspective. Unpublished Manuscript, Bloemfontein.

[54] Boverie, P.E. (1991) Human Systems Consultant: Using Family Therapy in Organizations. Family Therapy, 18, 61-71.

[55] Manning, T. (1991) Trends Transforming South Africa. Juta, Cape Town.

[56] Kreitner, R. and Kinicki, A. (1998) Organizational Behavior. Mcgraw-Hill, Boston.

[57] Old, D.R. (1995) Consulting for Real Transformation, Sustainability, and Organic Form. Journal of Organizational Change Management, 8, 6-17. http://dx.doi.org/10.1108/09534819510090123

[58] Joiner, C.W. (1987) Leadership for Change. Ballinger, Cambridge.

[59] Kotter, J.P. (1990) A Force for Change: How Leadership Differs From Management. The Free Press, New York.

[60] Bass, B.M. (1985) Bass and Stogdill’s Handbook of Leadership: Theory, Research and Managerial Applications. 3rd Edition, Free Press, New York.

[61] Avolio, B.J. and Bass, B.M. (2004) Multifactor Leadership Questionnaire Manual and Sampler Set. 3rd Edition, Mind Garden, Palo Alto.

[62] Northouse, P.G. (2007) Leadership: Theory and Practice. 4th Edition, Sage, Thousand Oaks.

[63] Hautala, T.M. (2006) The Relationship Between Personality and Transformational Leadership. Journal of Management 
Development, 25, 777-794. http://dx.doi.org/10.1108/02621710610684259

[64] Hinkin, T.R. and Schriesheim, C.A. (2008) A Theoretical and Empirical Examination of the Transactional and NonLeadership Dimensions of the Multifactor Leadership Questionnaire (MLQ). The Leadership Quarterly, 19, 501-513. http://dx.doi.org/10.1016/j.leaqua.2008.07.001

[65] Bass, B.M. and Avolio, B.J. (1993) Transformational Leadership and Organizational Culture. Public Administration Quarterly, 17, 112-121.

[66] Caldwell, B.J. and Spinks, J.M. (1999) Beyond the Self-Managing School Student Outcomes and the Reform of Education Series. Falmer Press, London.

[67] Sergiovanni, T.J. (1990) Supervision: A Redefinition. 5th Edition, Mcgrath, New York.

[68] Silins, H.C. (1994) The Relationship between Transformational and Transactional Leadership and School Improvement Outcomes. School Effectiveness and School Improvement, 5, 272-298. http://dx.doi.org/10.1080/0924345940050305

[69] Swail, W.S. (2003) Responding Responsibility. Change, 12, 10-19.

[70] Newstorm, J.W. (2008) Leaders \& the Leadership Process: Readings, Self-Assessment \& Applications. 5th Edition, Mcgraw-Hill/Irwin, New York.

[71] Shieh, H.L., Mills, M.E. and Waltz, C.F. (2001) Academic Leadership Style Predictors for Nursing Faculty Job Satisfaction in Taiwan. Journal of Nursing Education, 40, 203-209.

[72] Chen, S.H., Yang, C.C., Shiau, J.Y. and Wang, H.H. (2006) The Development of an Employee Satisfaction Model for Higher Education. The TQM Magazine, 18, 484-500. http://dx.doi.org/10.1108/09544780610685467

[73] Reuvers, M., Van Engen, M.L., Vinkenburg, C.J. and Wilson-Evered, E. (2008) Transformational Leadership and Innovative Work Behaviour: Exploring the Relevance of Gender Differences. Creativity and Innovation Management, 17, 227-244. http://dx.doi.org/10.1111/j.1467-8691.2008.00487.x

[74] Tichy, N.M. and De Vanna, M.A. (1990) The Transformational Leader. John Wiley, New York.

[75] Bennis, W.G. and Nanus, B. (1985) Leaders: The Strategies for Taking Charge. Harper \& Row, New York.

[76] Bowman, R.F. (2002) The Real Work of Department Chair. The Clearing House, 75, 158-162. http://dx.doi.org/10.1080/00098650209599258

[77] McArthur, R.C. (2002) Democratic Leadership and Faculty Empowerment at the Community College: A Theoretical Model for the Department Chair. Community College Review, 30, 1-10. http://dx.doi.org/10.1177/009155210203000301

[78] Sirat, M.B. (2010) Strategic Planning Directions of Malaysia’s Higher Education: University Autonomy in the Midst of Political Uncertainties. Higher Education, 59, 461-473. http://dx.doi.org/10.1007/s10734-009-9259-0

[79] Thomas, J.R. and Schuh, J.H. (2004) Socializing New Chairs. New Directions for Higher Education, 2004, 11-25.

[80] Middlehurst, R. (2004) Changing Internal Governance: A Discussion of Leadership Roles and Management Structures in UK Universities. Higher Education Quarterly, 58, 258-279. http://dx.doi.org/10.1111/j.1468-2273.2004.00273.x

[81] Oshagbemi, T. (1997) Job Satisfaction and Dissatisfaction in Higher Education. Education + Training, 39, $354-359$. http://dx.doi.org/10.1108/00400919710192395

[82] Pihie, Z.A.L., Akaria, K. and Sharifah, M.N. (2004) Leadership Practices of Principals of Sekolah Harapan Negara: A Comparative Study. In: Rahimah, H.A. and Tie, F.H., Eds., Principal Ship and School Management, 133-142.

[83] Griffin, R.W. and Moorhead, G. (2006) Fundamentals of Organizational Behavior: Managing People and Organizations. Houghton Mifflin Company, Boston.

[84] Lo, M.C., Ramayah, T. and de Run, E.C. (2010) Does Transformational Leadership Style Foster Commitment to Change? The Case of Higher Education in Malaysia. Procedia-Social and Behavioral Sciences, 2, 5384-5388. http://dx.doi.org/10.1016/j.sbspro.2010.03.877

[85] Sadeghi, A. and Pihie, Z.A.L. (2012) Transformational Leadership and Its Predictive Effects on Leadership Effectiveness. International Journal of Business \& Social Science, 3, 186-197.

[86] Voon, M.L., Lo, M.C., Ngui, S.K. and Peter, S. (2010) Leadership Styles in Context of Institution of Higher Education in Malaysia. http://www.google.com.my/

[87] Gous, M. (2003) Leadership in Support of Learning for an Unknown Future. Paper Presented at the HERTDSA 2003 Conference. http://surveys.canterbury.ac.nz/herdsa03/pdfsnon/N1071.pdf

[88] Leithwood, K.A. (1992) The Move toward Transformational Leadership. Educational Leadership, 49, 8-12.

[89] Taylor, T.V. (2002) Examination of Leadership Practices of Principals Identified as Servant Leaders. Unpublished Doctoral Dissertation, University of Missouri, Columbia. 
[90] Kouzes, J.M. and Posner, B.Z. (1995) The Leadership Challenge: How to Keep Getting Extraordinary Things Done in Organizations. Jossey-Bass, San Francisco.

[91] Kouzes, J.M. and Posner, B.Z. (2002) Leadership Challenge. 3rd Edition, Jossey-Bass, San Francisco.

[92] Eisenhart, M.A. (1991) Conceptual Frameworks for Research Circa 1991: Ideas from a Cultural Anthropologist; Implications for Mathematics Education Researchers. Proceedings of the 13th Annual Meeting of the North American Chapter of the International Group for the Psychology of Mathematics Education, Blacksburg, Vol. 1, 202-219.

[93] Howard, P., Cooke, S. and Butcher, J. (2007) Transformational Learning: An Aboriginal Educator's Aspirations, Supports and Celebrations. In: Butcher, J. and Mcdonald, L., Eds., Making a Difference: Challenges for Teachers, Teaching and Teacher Education, Sense Publishers, Rotterdam, 191-203.

[94] Argia, H.A.A. and Ismail, A. (2013) The Influence of Transformational Leadership on the Level of TQM Implementation in the Higher Education Sector. School of Educational Studies, Universiti Sains Malaysia, Penang.

[95] Bray, M. (2002) The Costs and Financing of Education: Trends and Policy Implications. CERC, Hong Kong.

[96] Lewin, K. (1947) Group Decision and Social Change. In: Newcomb, T. and Hartley, E., Eds., Readings in Social Psychology, Holt, Rinehart \& Winston, New York, 197-211.

[97] Cartwright, D. and Zander, A. (1953) Group Dynamics: Research and Theory. Row, Peterson, Evanston.

[98] Cartwright, D. and Zander, A. (1960) Group Dynamics: Research and Theory. 2nd Edition, Harper \& Row, Evanston.

[99] Burke, W. (1987) Organization Development: A Normative View. Addison-Wesley, Reading.

[100] Cummings, T. and Molloy, E. (1977) Improving Productivity and the Quality Ofwork Life. Praeger, New York.

[101] Viljone, J.P. and Rothmann, S. (2002) Transformation in a Tertiary-Education Institution: A Case Study. Management Dynamics, 11, 2-10.

[102] Mulatu, D. (2013) Best Skills for Educational Organization Leaders in a Global Society. Lambert Academic Publishing, Germany.

[103] Oliver, R. and Omari, A. (2002) Using Online Technologies to Support Problem Based Learning: Learners Responses and Perceptions. Australian Journal of Educational Technology, 15, 58-79.

[104] Morrow, P. (1993) The Theory and Measurement of Work Commitment. JAL, Greenwich.

[105] Steers, R. (1975) Problems in the Measurement of Organizational Effectiveness. Administrative Science Quarterly, 20, 546-558. http://dx.doi.org/10.2307/2392022

[106] Meyer, J. and Allen, N. (1997) Commitment in the Workplace. SAGE Publications, Thousand Oaks.

[107] Angle, H. and Perry, J. (1981) An Empirical Assessment of Organizational Commitment and Organizational Effectiveness. Administrative Science Quarterly, 26, 1-14. http://dx.doi.org/10.2307/2392596

[108] Liou, K. (1995) Understanding Employee Commitment in the Public Organization: A Study of the Juvenile Detention Center. International Journal of Public Administration, 18, 1269-1295. http://dx.doi.org/10.1080/01900699508525052

[109] Anderson, D. and Johnson, R. (1998) University Autonomy in Twenty Countries. Department of Employment, Education, Training and Youth Affairs, Canberra.

[110] Löscher, A. (2004) Developments in University Autonomy in England. Master's Dissertation, Centre for British Studies Humboldt University, Berlin.

[111] De Boer, H., Jongbloed, B., Enders, J. and File, J. (2010) Progress in Higher Education Reform across Europe: Governance Reform. European Commission, Brussels.

[112] Estermann, T. and Nokkala, T. (2009) University Autonomy in Europe I: Exploratory Study. European University Association, Brussels.

[113] Bogdan, R. (2003) Qualitative Research for Education: Introduction to Theories and Methods. 4th Edition, Pearson Education Inc., New York.

[114] Neuman, W.L. (2003) Social Research Methods. 5th Edition, Allyn \& Bacon, Boston.

[115] Merseth, K.K. (1994) Cases, Case Methods, and the Professional Development of Method in Social and Behavioural Research. Rutledge, Thousand Oaks, London, 297-319.

[116] Yin, R.K. (2003) Case Study Research: Design and Methods. Sage Publications Inc., Thousand Oaks.

[117] Yin, K. (1994) Case Study Research: Design and Methods. Sage Publications, Newbury Park.

[118] Brown, K.M. (2005) Reconciling Moral and Legal Collective Entitlement: Implications for Community-Based Land Reform. Land Use Policy, 24, 633-643.

[119] Tongco, M.D.C. (2007) Purposive Sampling as a Tool for Informant Selection. A Journal for Plant, People and Applied Research, 5, 147-158. 
[120] Tran, V.M. and Perry, J.A. (2003) Challenges to Using Neem (Azadirachta Indica Var. Siamensis Valenton) in Thailand. Economic Botany, 57, 93-102.

[121] Smith, B. (2000) Moral Foundations in Research with Human Participants. In: Sales, B. and Folkman, S., Eds., Ethics in Research with Human Participants, Educational Research, Washington, 3-10.

[122] Harrell, M.C. and Bradley, M.A. (2009) Data Collection Methods: Semi-Structured Interview and Focus Groups. RAND National Defense Research Institute, Santa Monica.

[123] Marvasti, A.B. (2004) Qualitative Research in Sociology: An Introduction. Sage Publications Inc., Thousand Oaks.

[124] Zikmund, W.G. (2003) Business Research Methods. 7th Edition, Thomson South Western, Ohio.

[125] Monica, C.A., Hesse-Biber, S.N. and Leavy, P. (2006) Emergent Methods in Social Research. Sage Publications Inc., Thousand Oaks.

[126] Viljone, J.P. and Rothmann, S. (2002) Transformation in a Tertiary-Education Institution: A Case Study. Management Dynamics, 11, 2-10.

[127] Hoodbhoy, P. (Ed.) (1998). Education and the State: Fifty-Five Years of Pakistan. Oxford University Press, Karachi. 


\section{Appendix}

\section{Addis Ababa University School of Graduate Studies}

Interview and FGD Guiding Questions to Academic and Supportive Staff of WSU

Purpose: This study examines the perception of academic and supportive staff toward their leadership in transforming Wolaita Sodo University. The questions categorized in to five parts based on the basic questions. Hence its purpose purely academic.

Category One: What are the views of staff towards their leadership in transforming Wolaita Sodo University?

1) What is transformation for you?

2) Do you think all change agents are aware of the transformation process under the institution? If so, what is your justification.

3) Do you think roles and responsibilities clearly assigned to all University workforces?

Category Two: To what extent academic leaders exhibit transformational leadership behaviors at Wolaita Sodo University?

4) Do you think that WSU is under transformation process? If so, what is your views and in what way?

5) Is the organizational system properly functioning from top to bottom to realize the transformation process?

6) To what extent organization and employees committed to realize the change process of WSU?

7) Do you think that BPR properly implemented in your University?

Category Three: To what extent does transformational change prevail at Woliata Sodo University?

8) Does your leaders equally show all transformational leadership behaviors like challenge the process, inspiring a shared vision, enabling other to act, modeling the way, encourage the heart (for more understanding read the details below).

9) Which leadership behavior highly realized under your institution?

10) Does your leaders stimulate followers to be creative and creative?

Category Four: What major challenges are encountering in the transformative change process at Wolaita Sodo University?

11) What are the major challenges that hinder the transformation process of the WSU?

Category Five:

12) Do you have any more comments on transformation of the University? 